\title{
A novel tubal sterilization technique to prevent recanalization: a preliminary study
}

\author{
Hemmanur Samartha Ram ${ }^{1 *}$, Illa Sai Samyuktha ${ }^{2}$, Nagashree V. ${ }^{1}$
}

\begin{abstract}
${ }^{1}$ Department of Obstetrics and Gynecology, Sandhyaram Maternity Hospital, Katampazhipuram, Palakkad, Kerala, India

${ }^{2}$ Department of Obstetrics and Gynecology, Divya Hospital Palladam Road, Tirupur, Tamil Nadu, India
\end{abstract}

Received: 21 December 2020

Revised: 05 February 2021

Accepted: 06 February 2021

\section{*Correspondence:}

Dr. Hemmanur Samartha Ram,

E-mail: drsamartharam@gmail.com

Copyright: (C) the author(s), publisher and licensee Medip Academy. This is an open-access article distributed under the terms of the Creative Commons Attribution Non-Commercial License, which permits unrestricted non-commercial use, distribution, and reproduction in any medium, provided the original work is properly cited.

\section{ABSTRACT}

Background: Spontaneous luminal recanalisation, and peritoneal fistula formation connecting the lumens of cut ends, are common causes for tubectomy failure. Failures rates are high with Pomeroy and Madlener methods. Uchida or Irvin techniques have lower failure rates. However, these techniques are not commonly practised because of technical complexity and long surgical time. We developed a novel surgical technique, which leaves the cut ends far away and peritonised.

Methods: In our hospital, modified Pomeroy method, and Parkland method were used during 2000- 09, and our new method was used during $2010-19$. In the new method, $0.5 \mathrm{~cm}$ of the cut end of the tube was turned inside and tied to the stump in such a way that the stumps get peritonised. The failure rates were compared between the groups.

Results: In the first group, 997 tubectomies were performed. Modified Pomeroy method was used in 360 women. Among them, one woman had a tubal ectopic pregnancy, and one woman had intrauterine pregnancy with a failure rate of $0.55 \%$. Parkland method was used in 637 women. Among them, two women had tubal ectopic pregnancies with a failure rate of $0.31 \%$. During the second 10 years, 637 tubectomies were performed using the new technique. None of the women had failure, with a failure rate of $0.0 \%$. This difference is statistically significant with $\mathrm{P}<001$.

Conclusions: New tubectomy method is simple, and more effective in preventing recanalization than Modified Pomeroy and Parklands methods.

Keywords: Novel tubal sterilisation technique, Prevent recanalization, Preliminary study

\section{INTRODUCTION}

Female sterilisation is a popular method of family planning (FP). It is estimated that about 180 million couples opt for this method of contraception worldwide. ${ }^{1}$ Ideally, sterilisation must be $100 \%$ effective, should not have any serious complications, and must be easily performed in an ambulatory care setting. ${ }^{2}$ Outcomes of failed tubectomy is an embarrassing situation for any obstetrician.

Spontaneous luminal recanalisation, and peritoneal fistula formation connecting the lumens of two cut ends, are the common causes for tubectomy failure. ${ }^{3}$ Tubal recanalisation may result in unwanted intrauterine pregnancy or dangerous tubal ectopic pregnancy. Ruptured tubal ectopic pregnancy is one of the major causes of maternal deaths. Surgical methods that leave the cut edges close together at the end of surgery have higher failure rates than the methods that leave the cut edges far away.

Laparoscopic ring application, Modified Pomeroy method, and Madlener method, leave the cut ends close together at the end of the surgery, and their reported failure rates are $1.7 \%, 0.3-0.4 \%$, and $2 \%$ respectively. ${ }^{4,5}$ 
In Parkland method, a segment of the fallopian tube is excised, and the cut ends are left apart. The failure rate in this method is $0.25 \% .^{6}$ In Uchida method, the failures are rare in which the proximal cut end is buried into mesosalpinx. In Irwing method, the failures are rare in which the proximal cut end is buried in the myometrium. ${ }^{6}$ Though the failure rates are lowest with Uchida and Irwing methods, these methods are not being practised by many, because of the complexity of the techniques, and the prolonged surgical time required. Recanalization can be prevented by peritonising the cut ends of the tubes.

The objective of this study is to develop a novel surgical technique, in which the cut ends stay far away, and get peritonised at the end of the surgery, which is simple, easily practicable and can prevent recanalisation.

\section{METHODS}

This is a retrospective comparative study conducted at Sandhyaram Maternity Hospital, Katampazhipuram, Palghat, Kerala. The data was collected from two separate 10year periods, a total of 20years, i.e. between January 2000 Jan and December 2019. All women over 18years, who had at least two children requesting for sterilisation were considered for tubectomy. All the patients who underwent tubectomy in our hospital during the duration mentioned above were included in the study. Informed written consent was obtained from all subjects who participated in this study. This study was confined to the standards of declarations of Helsinki. Modified Pomeroy method and Parkland method was used in the first ten years, whereas our new tubectomy method was used in the next ten years. The demographic details of the patients, details of the number of tubectomies performed using different surgical methods, and the number of tubectomies that failed with each method were obtained from our hospital records. Data was entered into Microsoft Excel datasheet and was analysed using SPSS 22 version software (IBM SPSS Statistics, Somers NY, USA). Categorical data was represented in the form of frequencies and proportions. Student t-test was used to compare the difference between the various methods.

\section{Modified pomeroy technique for tubal occlusion}

After transfixing a suture with '0' chromic catgut in an avascular area of the mesosalpinx, the proximal side of the tube is tied. Then with the same catgut, the distal side of the loop of the tube is secured and tied with a square knot. Then the loop of the tube was excised and removed. This leaves the cut ends of the tubes close together at the end of surgery.

\section{Parkland method}

A segment of the fallopian tube with an avascular area of mesosalpinx is picked up with Babcock forceps. Then the loop segment of the tube is excised after ligating both ends of the tube with catgut. This leaves the raw cut ends to stay apart.

\section{Detail of our new procedure}

In our method, a loop of the fallopian tube with avascular mesosalpinx is held and lifted up with Allis forceps (Figure $1 \mathrm{~A}$ ).

About $30 \mathrm{~cm}$ length of ' 00 ' chromic catgut was loaded to a round body needle, and the needle was brought to the middle of the catgut (Figure 1A).

The needle was passed through the mesosalpinx and brought to the opposite side. The needle end of the catgut was cut, and the catgut was made into two equal pieces (Figure $1 \mathrm{~B}$ and $\mathrm{C}$ ).

Each piece of catgut was used to transfix and ligate both proximal and distal ends of the loop (Fig 1 D).

With scalpel blade, mesosalpinx and the loop of the tube was cut and separated (Figure $2 \mathrm{E}$ ).

Allis forceps was applied to the tip of the cut end of the tube or endo salpinx, and it was left to hang down. Then the proximal part of the tube, $5 \mathrm{~mm}$ away from the ligature was caught with straight artery forceps and lifted up (Figure $2 \mathrm{~F}$ )

Squire ligature was applied, which resulted in the formation of a globe-like end of the tube covered with peritoneum. (Figure $2 \mathrm{G}$ )

Similar procedure was repeated to the other cut end of the tube. At the end of the surgery, two globular cut ends of the tube covered by peritoneum stay about $1.5 \mathrm{~cm}$ apart (Figure $2 \mathrm{H}$ ).

A video of the procedure can be viewed using the following link: https://youtu.be/nwe32aBI-Lc.

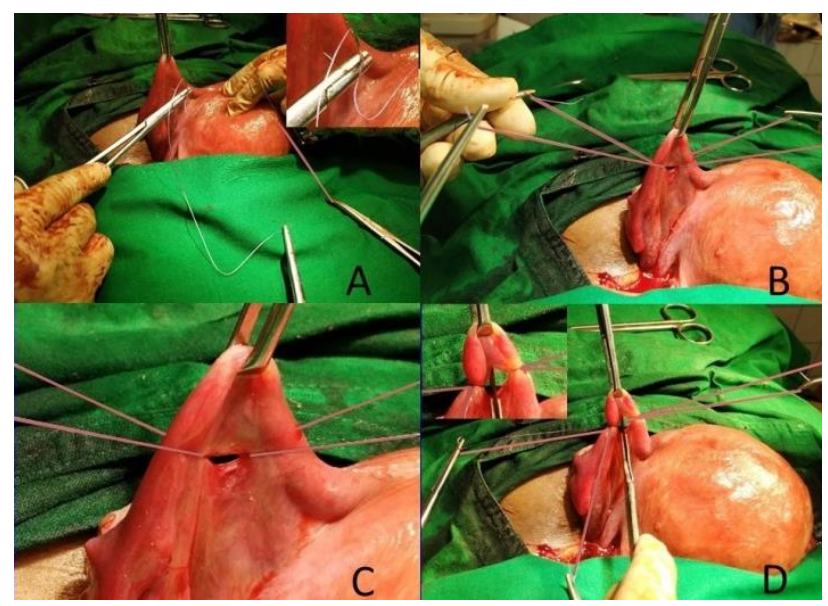

Figure 1: Steps of the procedure. 


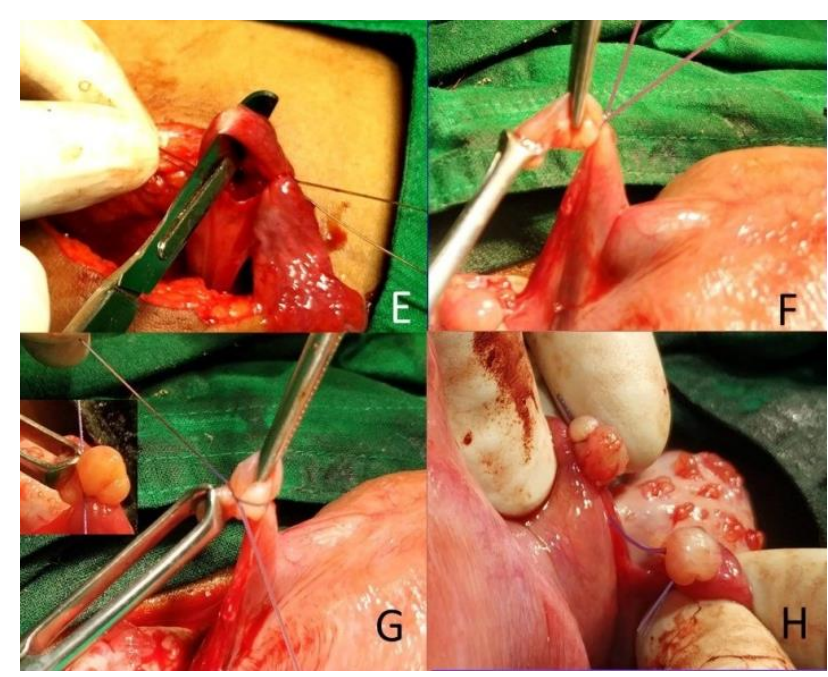

Figure 2: Steps of the procedure.

\section{RESULTS}

The study included women between 23 to 39 years. The mean age of the patients undergoing Modified Pomeroy was 28.56-5.64 years, Parkland method was 25.455.67years and our novel method was 26.45-4.76 years. The difference between the groups was not statistically significant $(\mathrm{P}=0.19)$. The frequency distribution of women with the number of children is shown in Figure 3.

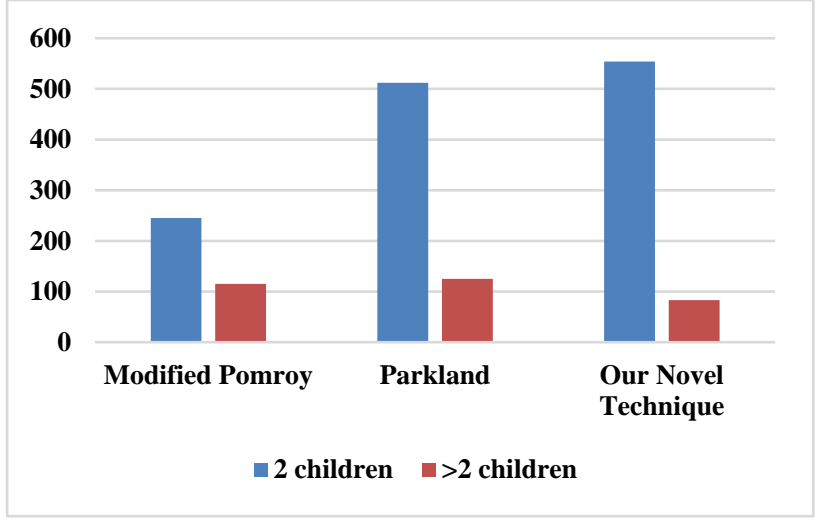

Figure 3: Frequency distribution of women with the number of children.

In the first ten years, 997 tubectomies were performed with four tubectomy failures. Modified Pomeroy method was used in 360 women; among them, two failures were observed with a failure rate of $0.55 \%$. One woman had a tubal ectopic pregnancy, and then another woman had intrauterine pregnancy. Parkland method was used in 637 women; among them, two women had tubal ectopic pregnancies with a failure rate of $0.31 \%$. During the second 10 years' period, 637 tubectomies were performed using our new technique, and none of the women had tubectomy failure, with a failure rate of $0.0 \%$ (Table 1 ). This difference is statistically significant with $\mathrm{P}<001$.

Table 1: Frequency distribution of the number of failures among various surgical methods performed.

\begin{tabular}{|llllll|}
\hline $\begin{array}{l}\text { Surgical method } \\
\text { used }\end{array}$ & Number of subjects & No of failures & TEP & IUP & $\begin{array}{l}\text { Failure rate } \\
(\%)\end{array}$ \\
\hline Modified pomeroy & 360 & 2 & 1 & 1 & 0.55 \\
\hline Parkland method & 637 & 2 & 2 & 0 & 0.31 \\
\hline New method & 637 & 0 & 0 & 0 & 0 \\
\hline
\end{tabular}

TEP: Tubal ectopic pregnancies; IUP: Intrauterine Pregnancies.

\section{DISCUSSION}

Tubectomy failure results in an unwanted intrauterine pregnancy or dangerous tubal ectopic pregnancy. Tubal ectopic pregnancy is the leading cause of maternal death in the first trimester and accounts for $10 \%-15 \%$ of all maternal deaths. ${ }^{7}$ Inadequate or no knowledge about ruptured ectopic pregnancy, vague nature of early symptoms, sudden hypovolemic shock, and inability to reach competent health facility within time, are the reasons for maternal deaths in rural areas of developing countries. ${ }^{8}$ For the same reason, there is every need for better tubectomy methods to prevent recanalisation and ectopic pregnancies.

Inherent biological efforts like luminal recanalisation and peritoneal fistula formation to connect the cut ends of the tube are the common causes for tubectomy failures. ${ }^{9}$ Failures do occur even with methods like Parkland method, in which $1.5 \mathrm{~cm}$ length of the tube is excised and removed. In Parkland method, the cut tubal stumps with its mesosalpinx freely move after surgery, and there is a likely chance for the cut ends coming close together and get adherent. The chances of the cut ends sticking together become less if the cut ends are peritonised. In our present method, we peritonised the cut ends of the tube by utilising the loop of the tube, which is usually excised and removed. In our study, the failure rate of the Pomeroy method was (2/360 women) $0.55 \%$, and Park Land method was (2/637 women) $0.31 \%$. These results are similar to the results of earlier studies. ${ }^{4,5} \mathrm{We}$ had four failures for 997 tubectomies (0.5\%) between 2000- 2009, whereas we did not have a single failure $(0.0 \%)$ with our new tubectomy method in 735 tubectomies during 20102019. This difference is statistically significant $(<0.001)$.

Limitations: This is a retrospective analysis with two different study durations. Also, the sample size is small. 
In this regard, randomised control trials are needed to prove the efficacy of our new technique with a larger sample size

\section{CONCLUSION}

The new tubal sterilisation method is technically sound, easily practicable, leaves the cut ends peritonised, leaves the cut ends apart, and with no failures, and can bring down maternal mortality related with ectopic pregnancy.

\section{ACKNOWLEDGMENTS}

We, authors sincerely acknowledge the support given by the staff of Obstetrics and gynaecology department of Sandhyaram Hospital, Katampazhipuram in conducting this study.

\section{Funding: No funding sources}

Conflict of interest: None declared

Ethical approval: The study was approved by the Institutional Ethics Committee

\section{REFERENCES}

1. Female Sterilisation. Contraceptive sterilisation: global issues and trends. New York: Engender Health; 2002.

2. Lawrie TA, Nardin JM, Kulier R, Boulvain M. Techniques for the interruption of tubal patency for female sterilisation. Cochrane Database Syst Rev. 2011;16(2):CD003034.
3. McCausland AM. Recanalization and fistulisation of the fallopian tubes are thought to be the causes of pregnancies following female sterilisation; Am J Obstet Gynecol. 1981;139(1):114-5.

4. Varma R, Gupta JK. Predicting negligence in female sterilisation failure using time interval to sterilisation failure: analysis of 131 cases. Hum Reprod. 2007;22(9):2437-43.

5. Basava L, Roy P. Fellopy Rings or Modified Pomeroy's Technique for Concurrent Tubal Sterilization; J Obstet Gynaecol India. 2016; 66(Suppl 1):198-201.

6. Schmidt, E, Diedrich, J. Surgical Procedures for Tubal Sterilization; Glob. libr. women's med. 2014.

7. Taran FA, Kagan KO, Hübner M, Hoopmann M, Wallwiener D, Brucker S. The Diagnosis and Treatment of Ectopic Pregnancy. Dtsch Arztebl Int. 2015;112(41):693-705.

8. Panti A, Ikechukwu NE. Ectopic pregnancy at Usmanu Danfodiyo University Teaching Hospital, Sokoto: a ten-year review. Ann Niger Med. 2012;6(2):87-91.

9. McCausland AM. Recanalization and fistulisation of the fallopian tubes are thought to be the causes of pregnancies following female sterilisation. Am J Obstet Gynecol. 1981;139(1):114-5.

Cite this article as: Ram HS, Samyuktha IS,

Nagashree V. A novel tubal sterilization technique to prevent recanalization: a preliminary study. Int $\mathbf{J}$

Reprod Contracept Obstet Gynecol 2021;10:1448-51. 